\title{
Availability of Opal Photonic Crystal Films for Visualizing Heterogeneous Strain Evolution in Steels: Example of Lüders Deformation
}

\author{
Zhipeng YANG, ${ }^{1,2)}$ Motomichi KOYAMA, ${ }^{1,3) *}$ Hiroshi FUDOUZI, ${ }^{4)}$ Tomohiko HOJO $^{1)}$ and Eiji AKIYAMA ${ }^{1)}$ \\ 1) Institute for Materials Research, Tohoku University, Katahira 2-1-1, Aoba-ku, Sendai, Miyagi, 980-8577 Japan. \\ 2) Department of Quantum Science and Energy Engineering, Graduate School of Engineering, Tohoku University, Aramaki Aza \\ Aoba, Aoba-ku, Sendai, Miyagi, Japan. \\ 3) Elements Strategy Initiative for Structural Materials (ESISM), Kyoto University, Yoshida-honmachi, Sakyo-ku, Kyoto, 606- \\ 8501 Japan. \\ 4) National Institute for Materials Science, Sengen 1-2-1, Tsukuba, Ibaraki, 305-0047 Japan.
}

(Received on April 17, 2020; accepted on May 18, 2020; J-STAGE Advance published date: June 20, 2020)

\begin{abstract}
An opal photonic crystal film was applied to characterize local strain evolution associated with Lürders band propagation in an annealed low carbon steel. A local change in color of the opal film was observed, which corresponded to the propagation of the Lürders band. In particular, we carried out two tensile experiments for line and area analyses of RGB (Red-Green-Blue) values of the opal films pasted on the specimens. Both of the experiments clearly exhibited a quantitative correspondence between color variation and local strain evolution, namely, the present study demonstrated the potential of the opal films to analyze heterogeneous strain evolution in steels.
\end{abstract}

KEY WORDS: strain mapping; Lüders banding; opal film; RGB analysis; low carbon steel.

\section{Introduction}

Steels contain complex microstructures, which is an origin of the variety of mechanical properties. In particular, plastic strain-microstructure relation is key to control strengthductility balance. ${ }^{1)}$ The microstructural strain evolution in steels is significantly heterogeneous, ${ }^{2-4)}$ and hierarchical from $\mathrm{nm}$ to $\mathrm{mm}$ scales. ${ }^{5,6}$ Therefore, various strain visualization techniques with different spatial resolutions and ranges of view field, e.g. digital image correlation, ${ }^{7-9)}$ micro-grid marker method, ${ }^{10,11)}$ and sampling moiré method, ${ }^{12,13)}$ have been applied to characterize the heterogeneous strain distribution.

From a viewpoint of strain visualization, an opal photonic crystal film has been developed to detect strain evolution. ${ }^{14,15)}$ The opal film consists of silicone elastomer and polystyrene spherical particles, which is produced on a polyethylene terephthalate substrate. The polystyrene particles are structured to be face-centered cubic (FCC), and a $\{111\}$ plane of the FCC structure is aligned parallel to the film surface. The visible light with a specific wavelength can satisfy Bragg's condition of the FCC $\{111\}$ plane, which results in the corresponding color. When the opal

\footnotetext{
* Corresponding author: E-mail: koyama@imr.tohoku.ac.jp
}

film is pasted on a tensile specimen (Fig. 1), the spacing of the $\{111\}$ plane decreases with the tensile elongation of the specimen. Accordingly, the wavelength of the visible light, which satisfies Bragg's condition, decreases with the

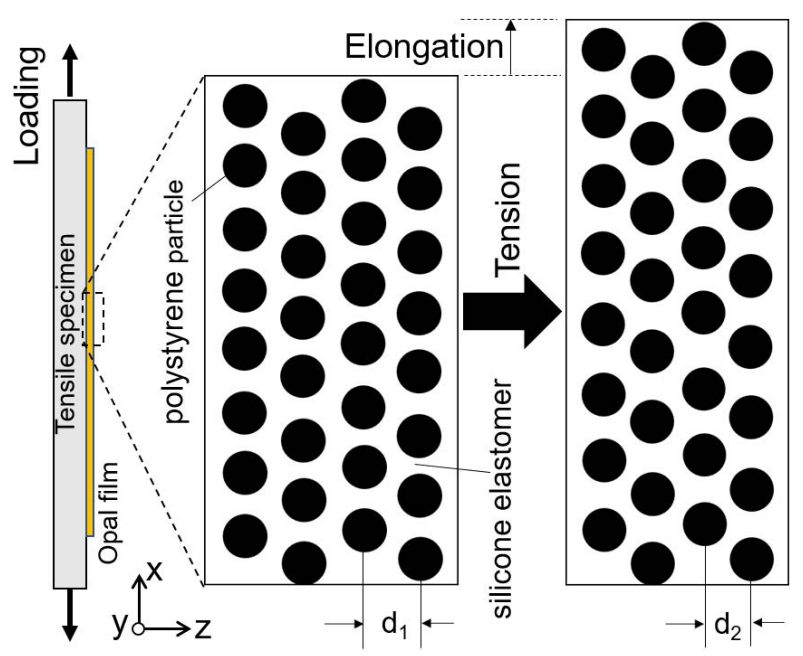

Fig. 1. A schematic for changes of polystyrene particle positions in the opal film, involved in tensile deformation. (Online version in color.) 
decrease in the spacing of $\{111\}$ plane. ${ }^{16,17)}$ Specifically, the peak wavelength $\lambda$ has a relation to $\varepsilon_{\mathrm{xx}}$ and $\varepsilon_{\mathrm{yy}}$ :

$$
\lambda=2 D\left(1-\frac{v}{1-v}\left(\varepsilon_{x x}+\varepsilon_{y y}\right)\right) \sqrt{n_{e f f}^{2}-\sin ^{2} \theta}
$$

where $D$ is initial spacing of particles, $v$ Poisson ratio of the film, $n_{\text {eff }}$ average refraction index, and $\theta$ incident angle. That is, strain can be visualized as the color of the opal film. Amazingly, the opal film size can be scaled up over $100 \mathrm{~cm}^{2}{ }^{18)}$ which thereby has been expected to be used for strain visualization of structural components.

In this study, we present availability of the opal film for characterizing heterogeneous strain evolution in steels. Specifically, as a first step, the opal film was used to visualize strain evolution involved in Lüders band propagation in a low carbon steel.

Table 1. Chemical composition of the steel used.

\begin{tabular}{|c|c|c|c|c|c|c|c|c|}
\hline \multirow{2}{*}{$\mathrm{S} 10 \mathrm{C}$} & $\mathrm{C}$ & $\mathrm{Si}$ & $\mathrm{Mn}$ & $\mathrm{P}$ & $\mathrm{S}$ & $\mathrm{Al}$ & $\mathrm{Cu}$ & $\mathrm{Fe}$ \\
\hline & 0.13 & 0.22 & 0.39 & 0.01 & 0.02 & 0.01 & 0.09 & Bal. \\
\hline
\end{tabular}

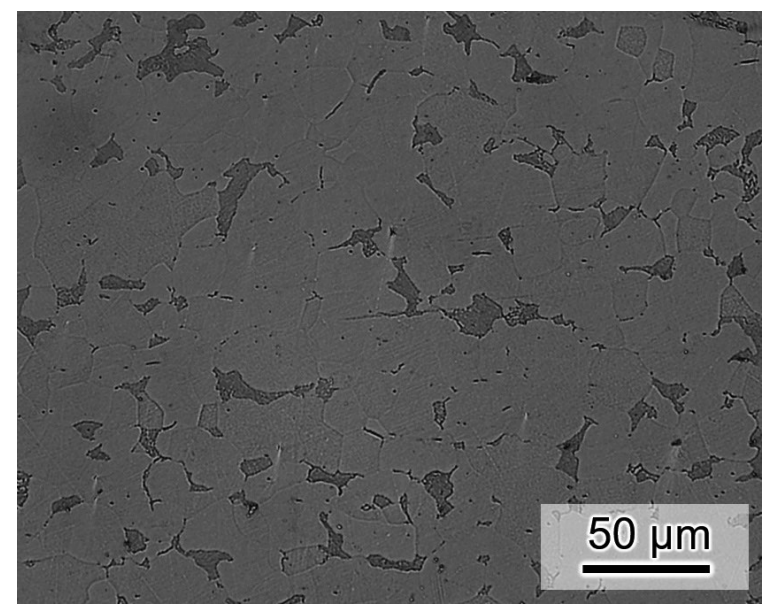

Fig. 2. Optical micrograph of the as-annealed steel. The polished surface was etched with $5 \%$ nital.

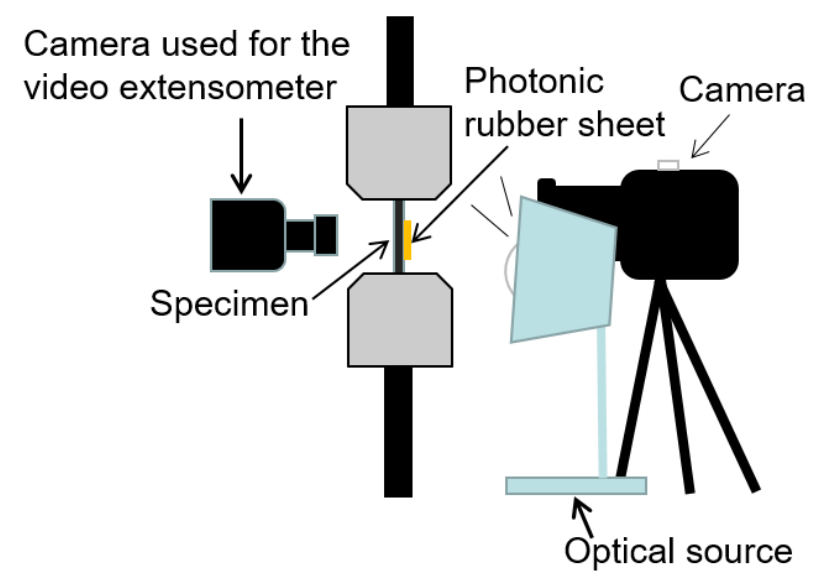

Fig. 3. A schematic of the experimental setup for strain visualization and measurement. (Online version in color.)

\section{Experimental Procedure}

\subsection{Material}

The chemical composition of the low carbon steel specimen (S10C) is listed in Table 1. The steel bar was annealed for $1 \mathrm{~h}$ at $900^{\circ} \mathrm{C}$ then cooled in a furnace. The annealed bar was cut by electric discharge machining (EDM) to prepare dog-bone type tensile specimens with gauge dimensions of $15 \mathrm{~mm}$ in length and $4 \mathrm{~mm}$ in width and $1 \mathrm{~mm}$ in thickness. The EDM-affected layer was removed by mechanical polishing using \#3000 emery paper, monocrystalline diamond suspension of $9 \mu \mathrm{m}, 3 \mu \mathrm{m}$ and colloidal silica with a particle size of $60 \mathrm{~nm}$.). The initial microstructure of the specimens was composed of ferrite and perlite as shown in Fig. 2.

\subsection{Strain Visualization Using Opal Film}

The size of the colloidal polystyrene particles in the present opal film was approximately $200 \mathrm{~nm}$. Because appearance of color would require a group of the particles, the maximum spatial resolution can be a few tens of $\mu \mathrm{m}$. However, the observation of the film was conducted by using a commercial digital camera with a low magnification, and thus, the spatial resolution in the present experiment was an order of sub-mm. The applicable strain level of the opal film has been confirmed to be over $30 \%$ tensile strain. The opal film was cut into the following dimensions: 15 $\mathrm{mm}$ in length and $4 \mathrm{~mm}$ in width. The opal film was pasted on the gauge section of the tensile specimen using a nonsolvent double pack type epoxy resin composition mixture: $2 \mathrm{ml}$ epoxy resin primer) $1 \mathrm{ml}$ epoxy resin curing agent. To avoid pollution of the opal films, the opal film surface was covered with tape, and then, pressed onto the specimen surface by putting plate weights for bonding. Because of disadvantageous effects of pasting/removing the tape and pressing by the weight (which perhaps made scratches, the localized flow of the adhesive, or peeling the polystyrene particles), a portion of the opal film surface was damaged, where the color appeared as dark red or black, and did not change with deformation. After pasting the opal film, the specimen pressed by the weight was exposed to air for 48 $\mathrm{h}$ at $25^{\circ} \mathrm{C}$. On the other side of the specimen surface, gauge marks were pasted to measure actual strains. Tensile tests were carried out at $25^{\circ} \mathrm{C}$ and $10^{-4} \mathrm{~s}^{-1}$. During the tensile tests, two types of video data were taken to characterize a variation of the color of the opal film and to measure the distance between the gauge marks. The experimental setup is schematically shown in Fig. 3.

\section{Results and Discussion}

\subsection{Variation of Color Contrast Associated with Lüders Banding}

Figure 4 shows the engineering stress-strain curves of the low carbon steel. Propagation of a Lüders band occurred immediately after the yielding, which resulted in $1.4 \%$ Lüders elongation on the stress-strain curve, which is typical deformation behavior of annealed carbon steels. ${ }^{19,20)}$

Figure 5 exhibits images that depict the color of the opal film pasted on the tensile specimen surface. The initial color was bright red, and the dark red indicates damaged regions mentioned in the experimental procedure section. In the 
subsequent experiment, only the non-damage region (bright red) shows a significant change in color. Immediately after yielding, the color of the opal film slightly changed at the upper end of the gauge section, and the region where the color changed propagated to the lower side, which corre-

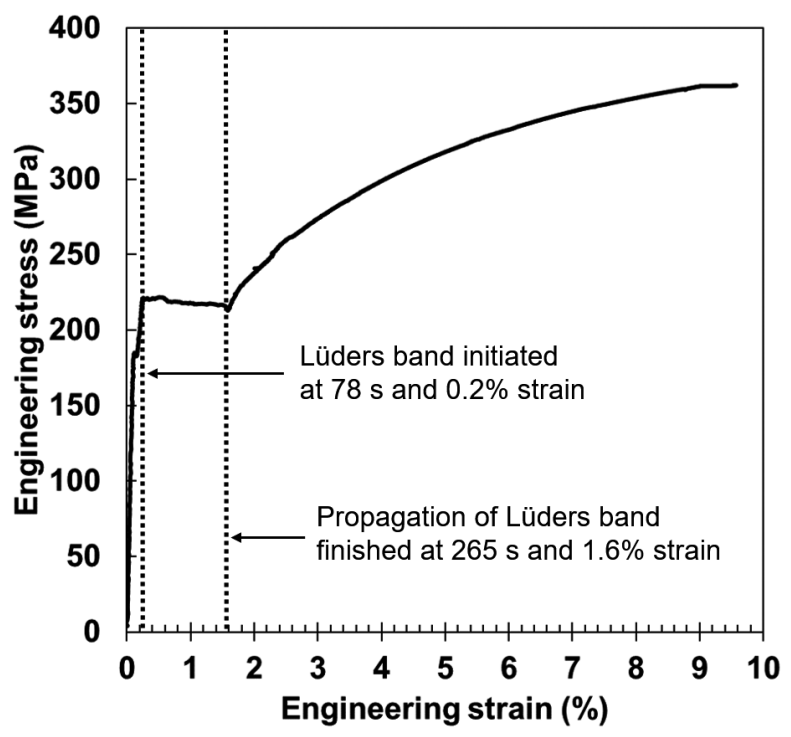

Fig. 4. Engineering stress-strain curve at an initial strain rate of $10^{-4} s^{-1}$. sponds to the initiation and propagation of a Lüders band. Further deformation induced another change in color at the other end of the gauge section, which also corresponds to initiation and propagation of another Lüders band (Fig. 5(b)). The two Lüders bands propagated until the fronts met each other (Figs. 5(b) to 5(d)). After the two Lüders

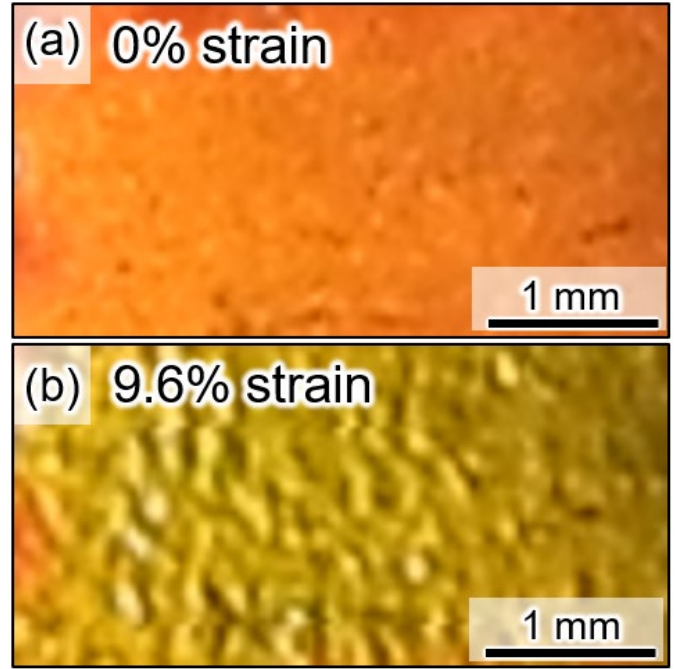

Fig. 6. (a, b) Magnifications of Figs. 5(a) and 5(f). (Online version in color.)

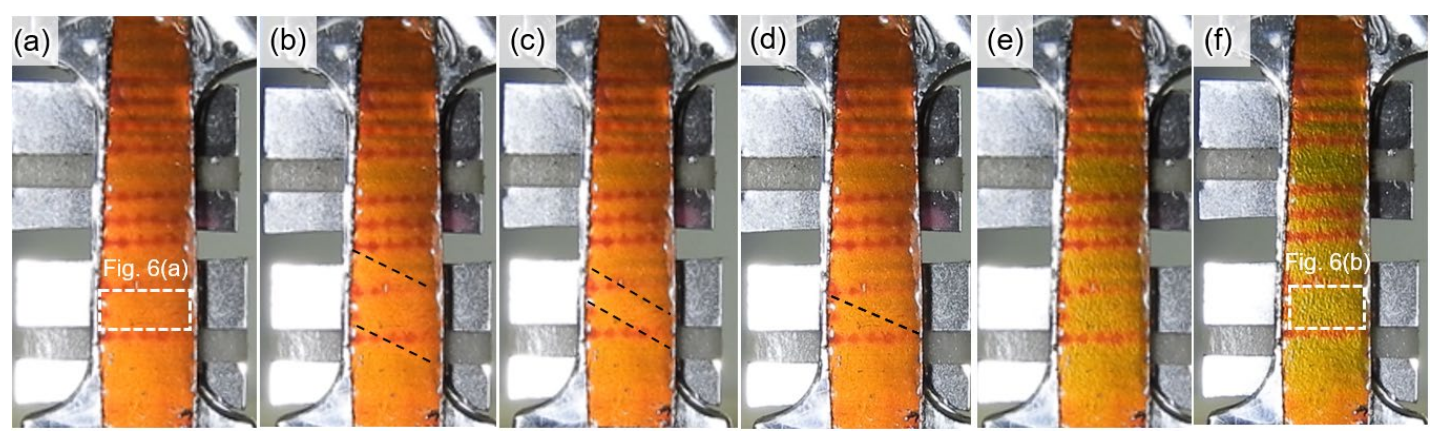

Fig. 5. Photos showing Lüders band propagation and associated color changes of the opal film at (a) $0 \mathrm{~s}, 0 \% \mathrm{strain}$, (b) $204 \mathrm{~s}, 1.2 \%$ strain, (c) $240 \mathrm{~s}, 1.4 \%$ strain, (d) 270 s, $1.6 \%$ strain, (e) 790 s, $5 \%$ strain, and (f) 1395 s, $9.6 \%$ strain. The black dashed lines indicate the positions of the Lüders fronts. These images were captured from video data. (Online version in color.)
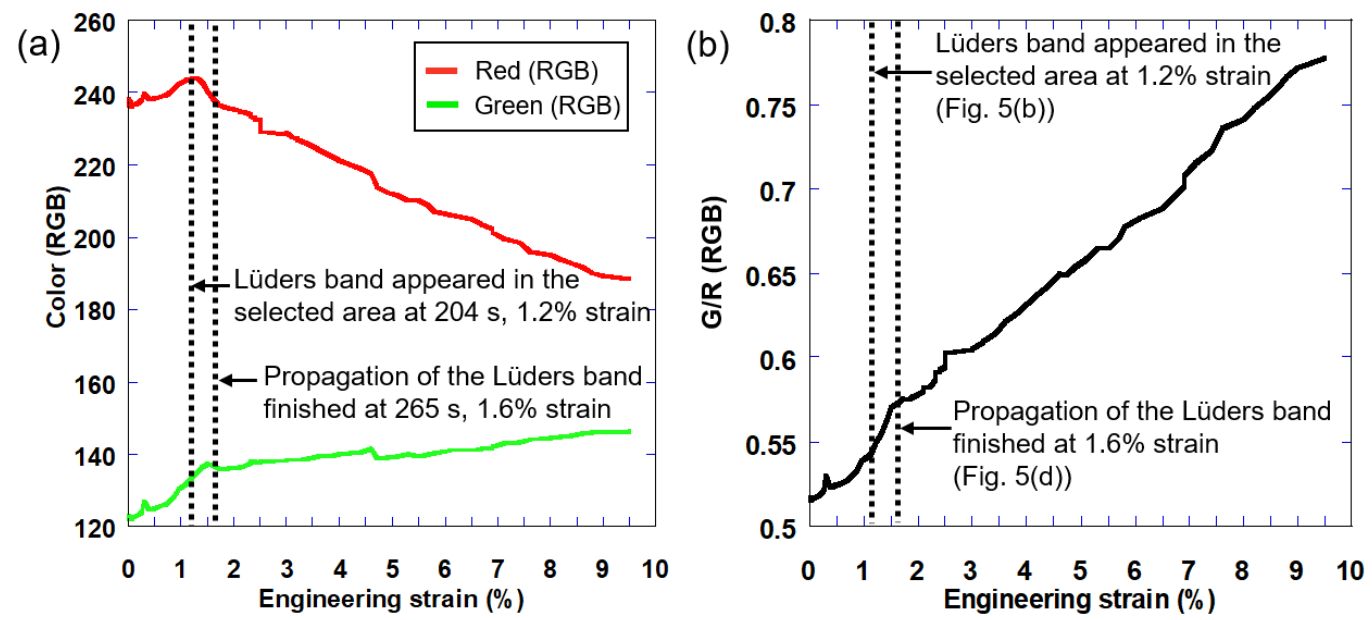

Fig. 7. (a) Relationship between macroscopic engineering strain and changes of red (R) and green (G) values in the confined region of Fig. 5. (b) Green values normalized by red values corresponding to (a). (Online version in color.) 
front met each other, the change of color got uniform in the gauge section (Fig. 5(e)). At the final stage of the deformation $(9.6 \%$ strain), the color of the opal film clearly changed from red to green as shown in the Fig. 5(f).

For more quantitative analyses of the strain evolution, a confined region was selected from the images of Fig. 5.
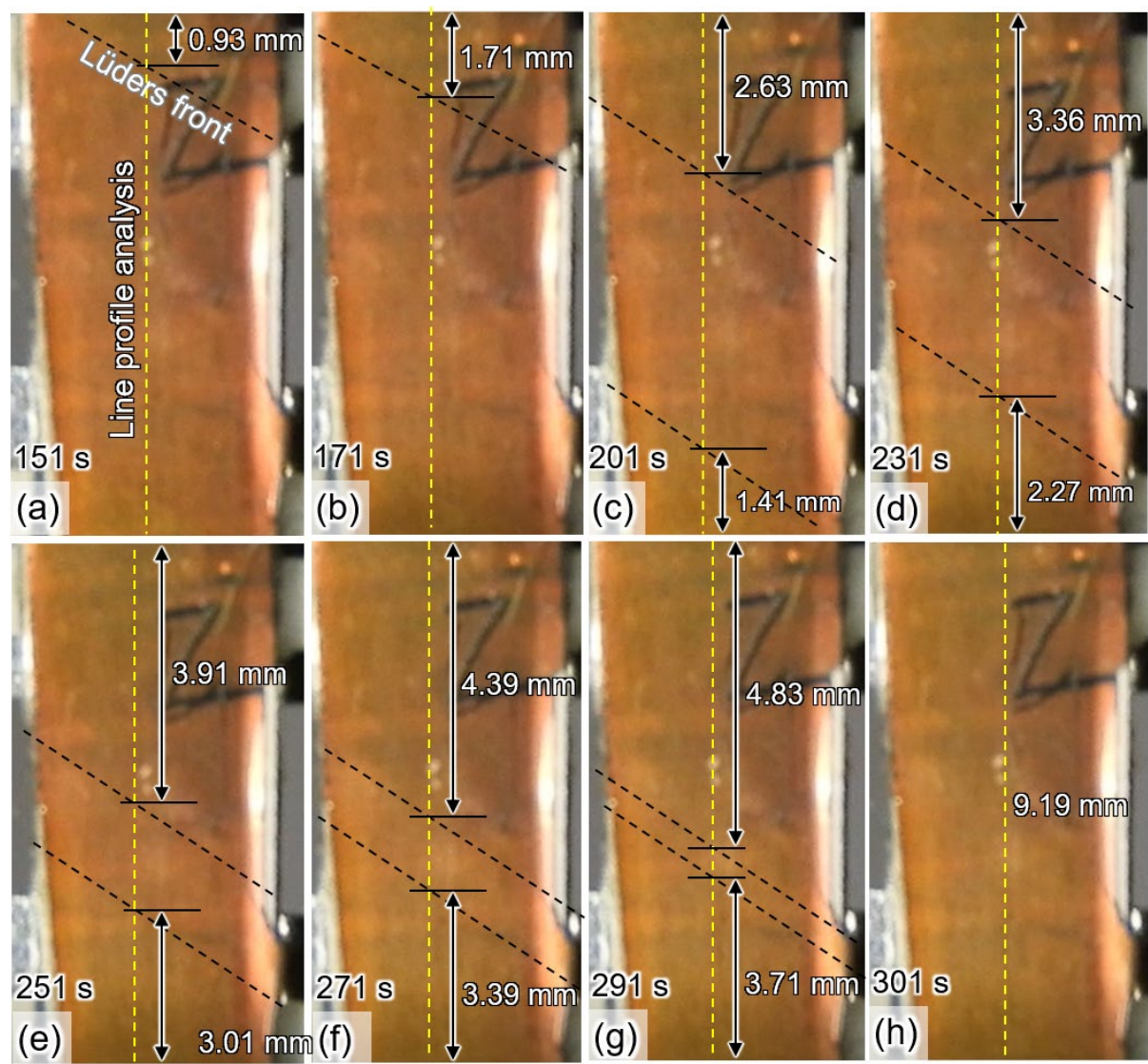

Fig. 8. Photos showing Lüders band propagation and associated color changes of the opal film at (a) $0.6 \%$, (b) $0.9 \%$, (c) $1.3 \%$, (d) $1.6 \%$, (e) $1.7 \%$, (f) $1.8 \%$, (g) $1.9 \%$, and (h) $2.0 \%$ strains. The black dashed lines indicate the positions of the Lüders fronts. The arrows and values indicate the distance of the Lüders band propagation from the top or bottom edge of each image along the yellow dashed lines used for profile analyses shown in Fig. 9. The black "Z" mark appeared during the procedure of pasting the opal film, which is a damaged region. The video data is also shown as supplementary material. (Online version in color.)
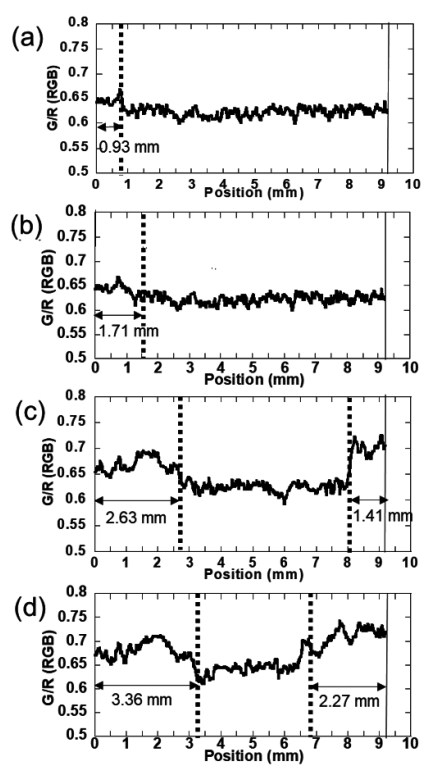

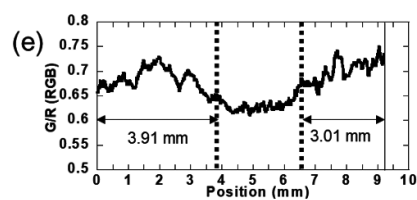

(f) $\begin{array}{r}0.8 \\ 0.75\end{array}$

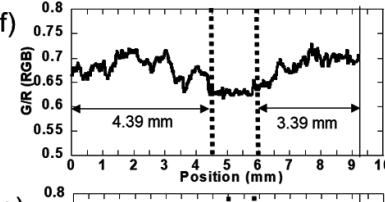

(g) $\begin{array}{r}0.8 \\ 0.75\end{array}$

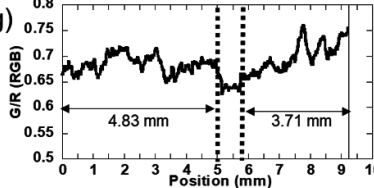

(h) 0.85

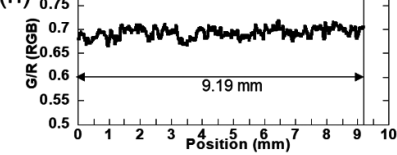

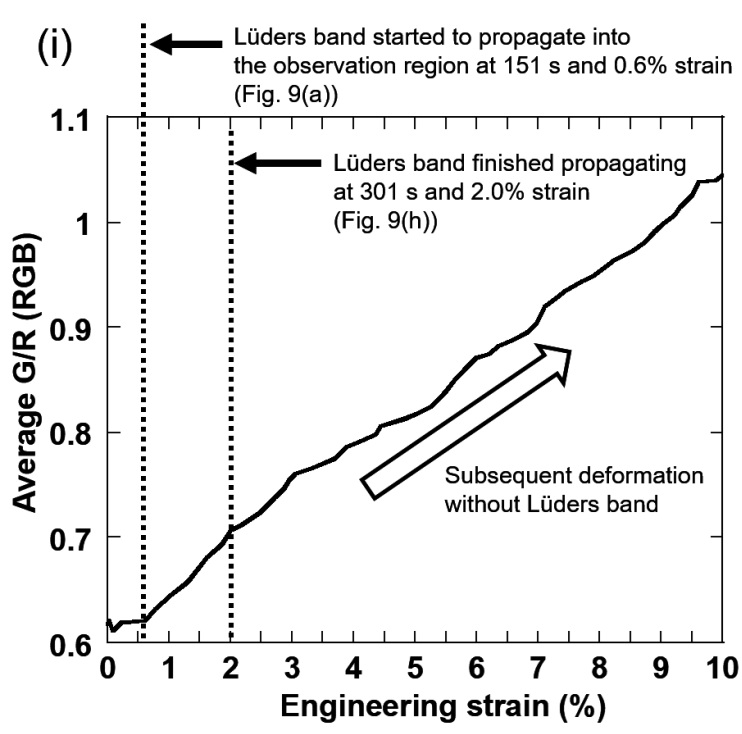

Fig. 9. Green values normalized by red values at (a) $151 \mathrm{~s}, 0.6 \%$ strain, (b) $171 \mathrm{~s}, 0.9 \%$ strain. (c) $201 \mathrm{~s}, 1.3 \%$ strain, (d) $231 \mathrm{~s}, 1.6 \%$ strain, (e) $251 \mathrm{~s}, 1.7 \%$ strain, (f) $271 \mathrm{~s}, 1.8 \%$ strain, (g) $291 \mathrm{~s}, 1.9 \%$ strain, and (h) $301 \mathrm{~s}, 2.0 \%$ strain. The dotted lines indicate positions of the Lüders fronts at each deformation stage. (i) Average G/R values plotted against engineering strain. 
Figure 6 exhibits examples of the images selected from Fig. 5. The confined and identical regions with different strain levels were characterized by using RGB (Red-Green-Blue) data. Figure 7(a) shows the changes of red and green values of the selected area plotted against macroscopic engineering strain. Red value rapidly decreased with strain after yielding, while green value increased as shown in Fig. 7(a). To clearly demonstrate the relative change in color, green values were normalized by red values $(\mathrm{G} / \mathrm{R})$, as shown in Fig. 7(b). The slope of Fig. 7(b) increased when the Lüders band started to propagate in the selected area and decreased when the Lüders band passed through the region. These facts indicate that the opal film is available to detect strain heterogeneity associated with the Lüders band propagation.

\subsection{Line Profile Change and its Correlation with Lüders Front Position}

Differently from the previous section, we here characterize line profiles of the color of the opal film, which is associated with Lürders band propagation. Similar to Fig. 4, the second experiment shown in Fig. 7 also demonstrates local color changes during the Lürders band propagation (Movie S1 (Supporting Information)). Figure 9 shows the line profiles of $\mathrm{G} / \mathrm{R}$ values along the dashed vertical yellow lines in each image of Fig. 8. The G/R values in the interior and exterior of the region where Lürders band swept were approximately $0.65-0.75$ and $0.60-0.65$, irrespective of macroscopic strain. Corresponding to the Lürders band propagation, the boundary between the relatively high and low G/R values moved (Figs. 9(a) to 9(e)), and the G/R values finally got nearly constant in the range of $0.65-0.70$ (Fig. 9(f)). Similar to Fig. 7(b), the average G/R value of each line profile showed a larger slope against strain when the propagation of the Lürders band affects the change in color, compared to that after the Lürders banding finished, as shown in Fig. 9(i).

To demonstrate the above-mentioned trend clearly, the variations of color in the interior and exterior of the Lürders banded region were analyzed separately. After the Lürders band appeared, the $G / R$ value in the interior of the Lürders

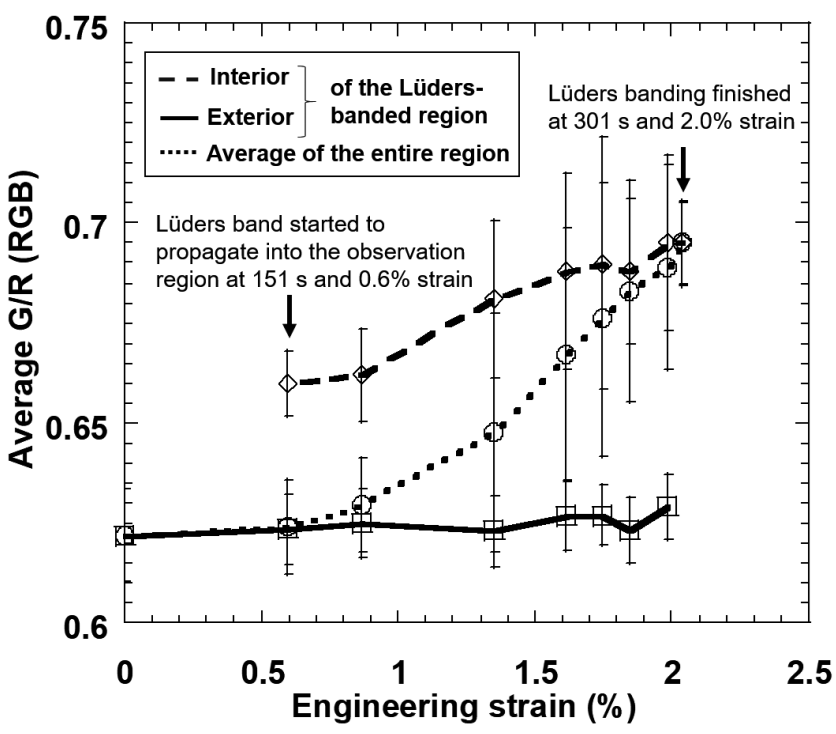

Fig. 10. Average $G / R$ values plotted against macroscopic engineering strain. banded regions increased from approximately 0.65 to 0.75 with increasing macroscopic strain, which is consistent with the line profile analyses. It is clearly seen that the strain dependence of the $G / R$ value in the interior of the Lüders banded region is much larger than that in the exterior.

\section{Conclusions}

We investigated the availability of artificial opal films for characterizing heterogeneous strain evolution in steels. As an example, we focused on the propagation of Lüders bands. When the specimen where the opal film was pasted on the surface was tensile-deformed, the RGB value showed a significant change with strain. Specifically, G/R values sharply increased when the Lüders bands propagated into the observation region. Both area and line analyses were successful, which showed a good correspondence with the positions of Lüders fronts. Hence, we conclude that the photonic opal crystal film has a high potential to characterize heterogeneous strain evolution in steels. To be more specific, the present technique is expected to be used for real in-situ strain mapping until a large plastic strain, because this is a fully optical method.

\section{Supporting Information}

The video data corresponding to Fig. 8 .

This material is available on the Website at https://doi. org/10.2355/isijinternational.ISIJINT-2020-223.

\section{Acknowledgements}

This work was supported by JSPS KAKENHI (JP20H02457).

\section{REFERENCES}

1) C. C. Tasan, M. Diehl, D. Yan, M. Bechtold, F. Roters, L. Schemmann, C. Zheng, N. Peranio, D. Ponge, M. Koyama, K. Tsuzaki and D. Raabe: Annu. Rev. Mater. Res., 45 (2015), 391.

2) X. G. Wang, C. H. Liu, B. B. He, C. Jiang and M. X. Huang: Mater. Sci. Eng. A, 761 (2019), 138050.

3) M. I. Latypov, S. Shin, B. C. De Cooman and H. S. Kim: Acta Mater., 108 (2016), 219.

4) T. Kaneko, M. Koyama, T. Fujisawa and K. Tsuzaki: ISIJ Int., 56 (2016), 2037.

5) N. Nakada, M. Nishiyama, N. Koga, T. Tsuchiyama and S. Takaki: Tetsu-to-Hagané, 100 (2014), 1238 (in Japanese).

6) L. Morsdorf, O. Jeannin, D. Barbier, M. Mitsuhara, D. Raabe and C. C. Tasan: Acta Mater., 121 (2016), 202.

7) B. Pan, K. Qian, H. Xie and A. Asundi: Meas. Sci. Technol., 20 (2009), 062001.

8) J. Kang, Y. Ososkov, J. D. Embury and D. S. Wilkinson: Scr. Mater., 56 (2007), 999.

9) M. Koyama, Y. Tanaka and K. Tsuzaki: Exp. Mech., 58 (2018), 381.

10) H. Minami, H. Ikeda, T. Morikawa, K. Higashida, T. Mayama, Y. Toji and K. Hasegawa: Tetsu-to-Hagané, 98 (2012), 303 (in Japanese).

11) N. Ishikawa, K. Yasuda, H. Sueyoshi, S. Endo, H. Ikeda, T. Morikawa and K. Higashida: Acta Mater., 97 (2015), 257.

12) P. G. Ifju and B. Han: Exp. Mech., 50 (2010), 1129.

13) Q. Wang, S. Ri, H. Tsuda, M. Koyama and K. Tsuzaki: Opt. Express, 25 (2017), 13465.

14) D. Zonta, A. Chiappini, A. Chiasera, M. Ferrari, M. Pozzi, L. Battisti and M. Benedetti: Proc. SPIE, 7292 (2009), 729215.

15) H. Fudouzi, T. Sawada, Y. Tanaka, I. Ario, T. Hyakutake and I. Nishizaki: Proc. SPIE, 8345 (2012), 83451S.

16) H. Fudouzi and T. Sawada: Langmuir, 22 (2006), 1365.

17) A. Chiappini, A. Piotrowska, M. Marciniak, M. Ferrari and D. Zonta: Proc. SPIE, 9435 (2015), 94350J.

18) H. Fudouzi: J. Colloid Interface Sci, 275 (2004), 277.

19) H. B. Sun, F. Yoshida, M. Ohmori and X. Ma: Mater. Lett., 57 (2003), 4535.

20) N. Tsuchida, Y. Tomota, K. Nagai and K. Fukaura: Scr. Mater., 54 (2006), 57. 